\title{
Influence of a nine-day alpine ski training programme on the postural stability of people with different levels of skills
}

\author{
Michał Staniszewski ${ }^{1}$, Przemysław Zybko ${ }^{1}$, Ida Wiszomirska ${ }^{2}$ \\ ${ }^{1}$ Faculty of Physical Education, Józef Piłsudski University of Physical Education, Warsaw, Poland; ${ }^{2}$ Faculty of \\ Rehabilitation, Józef Piłsudski University of Physical Education, Warsaw, Poland
}

\section{Summary}

Study aim: In alpine skiing, balance is one of the key elements that determine the effectiveness of the ride. Because of ski boots, the foot and ankle joint complex is excluded from the process of maintaining the stability of the body. The aim of the study was to determine to what extent a few days of skiing activities and the level of technical skills affect the skiers' level of postural stability.

Material and methods: The study involved 10 beginner $(20.7 \pm 1.1$ years, $76.4 \pm 8.7 \mathrm{~kg}, 184.4 \pm 6.1 \mathrm{~cm})$ and 10 advanced $(20.5 \pm 0.5$ years, $80.5 \pm 13.7 \mathrm{~kg}, 184.5 \pm 9.5 \mathrm{~cm})$ skiers, who participated in a nine-day ski training camp. Measurements of the postural stability were taken on the first and last days of the camp, on an AccuSway (AMTI, USA) stabilometric platform.

Results: In both groups, a significant $(\mathrm{p}<0.05)$ improvement in stability was observed after the training camp only while standing in ski boots. While standing on two feet, the participants were more stable barefoot $(\mathrm{p}<0.05)$, and when standing on one foot they were more stable in the ski boot trial $(\mathrm{p}<0.05)$.

Conclusions: Skiing had a positive effect on the postural stability only in measurement conditions that were similar to those in which this stability was practiced, i.e. in measurements involving ski boots. The restriction of mobility within the ankle joint significantly influenced the training-induced changes in the postural stability of both beginner and advanced alpine skiers.

Key words: Ski boots - Balance - Ankle joint - Biomechanics

\section{Introduction}

Alpine skiing is an outdoor winter sport in which movement is generated by external forces, mainly gravity [12]. Unlike most sports, the technique used for movements in skiing is not aimed at generating a progressive or circular motion, because the lower (locomotive) limbs are immovably attached to the skis by ski boots and fastened with bindings. In skiing, maintaining a stable position during the descent and changing the direction of movement is done by balancing the body, i.e. by deliberately losing balance in the direction of the intended movement. The skier's position while moving down the slope can be compared to an inverted pendulum whose anchor point consists of the skis guided on the snow [18]. However, publications on issues related to the biomechanics of a descent, with particular emphasis on the balance parameters, are rare in the literature on alpine skiing [10].

For the body to remain in balance, its centre of mass must project onto the base of support (BOS), the limits of which are determined by the contours of the feet in a standing position. The shape and size of the base of support depends on the position of the feet, which is why a person stands more firmly on two feet than on one. Both when standing and moving, the centre of mass moves in various directions. The condition of maintaining balance involves deviations of the centre of mass from the gravity axis only so much that it constantly remains within the limits of stability (LOS). The limits of stability of such bodily sways can be inscribed in a two-dimensional space that includes the maximum deflections of the centre of mass from a given base of support of the body while standing on two feet, on one foot or in another measurement position. This means that the centre of mass can move within the full extent of the limits of stability in tests on the maintenance of balance in both static and dynamic conditions $[4,8,14,15]$.

In skiing, there are additional conditions for the maintenance of balance. Alpine skis are designed in such a way that when they are put on their edge, they bend and start to descend in a curve. In order to turn, the skier must lean 
into the direction of the turn so that the projection of the centre of mass falls out of the area of the base of support. In this situation, a torque is created between the force of gravity and the force of the reaction of the snow on the skis, which results in a descent in a curve and a loss of balance. A stable position in a turn (fall prevention) is determined by a created inertial force which is directed outside of the turn, and depends on the skier's speed of movement and the radius of the turn (which is an apparent force that has the same value but an opposite sense of the centripetal force). Therefore, when in a turn, a skier's body remains in a condition of constant balance. In alpine skiing, balance is one of the key elements that determine the effectiveness of a ride $[13,16,23]$.

Three types of postural reactions to the loss of the body's balance can be observed. The first reaction is the myotatic stretch reflex, which appears in response to changes in the position of the ankle joints, and is recorded in the triceps surae muscles. This is the earliest mechanism, which increases the activity of the muscles surrounding the joint that is subject to destabilisation. The reflex caused by a myotatic stretch causes its contraction, which then results in the stiffening of the surrounding joints as a response to the stimulus that has disturbed the balance. For example, changes in the angle of the joints of the lower limbs are followed by a reflexive tensioning of the adjacent muscles. The subsequent release of the reaction prevents an excessive mobility of the joints and stabilises the posture once again. The next reflex in the process of balancing is the balance-correcting response, which appears in response to a strongly destabilising stimulus. This reaction has a multi-muscle range, and occurs almost simultaneously in the muscles of the lower limbs, torso and neck, while the mechanisms that initiate the reaction are centrally coordinated. The last of the three types of muscular reactions is the balance-stabilising response. In a situation of a sudden loss of balance, a stretch reflex first occurs and then is followed by a balance-correcting response, which prevents a fall. The subsequent stabilising responses then allow the body to return to a balanced position. In order to control the balance of the multi-element system which is the posture of body, the central nervous system must use several types of reflexive reactions that are controlled by the proprioceptors, the vestibular organ and the visual organ, depending on whether the changes of posture are controlled by corrective or by stabilising reactions [1].

The biomechanics of the human limbs and the human torso depend on the cooperative actions of various groups of muscle. The body's centre of mass (which is located in the lower part of the torso in a standing position) is separated from the feet (which form the base of support) by big pairs of joints such as the ankle joints, the knee joints and the hip joints. Therefore, to enable changes in the position of all of these elements in relation to each other while maintaining the balance of the whole posture, the mobility of each joint is controlled by pairs of muscle groups that act antagonistically [17].

Wearing ski boots imposes certain mechanical limitations on the level of liberty in the ankle joint [2]. The mechanisms responsible for the changes in the strategies of postural control while standing in ski boots can be considered from three aspects. First, the ski boots change the postural control of the body because they act as a support in the process of maintaining balance by stiffening the foot and the ankle joint, the elements of the biokinematic chain of the lower limbs that are closest to the base of support. Second, the ski boots provide an additional tactile stimulus, which is detected by the cutaneous receptors in the lower parts of the shins and the feet, as well as a mechanical stimulus, which is related to the support of the shin along the entire length of the tibia in contact with the ski boot's tongue. Third, by putting on ski boots, a skier increases the length of the sole which is in contact with the ground. In doing this, the skier also increases the length of the base of support, which can help him or her to maintain a stable position and to reduce the amplitude of sways in the sagittal plane [19].

The aim of the study was to examine how the mechanisms described above, which restrict the mobility of the foot and the ankle joint complex, affect the maintenance of a stable body posture in people with different levels of skiing skills. In addition, the study assessed the impact of participation in a nine-day ski training programme on the parameters of the stability of the body in beginner and advanced skiers. Therefore, the aim of the experiment was to determine to what extent a few days of skiing activities and the level of technical skills affected the level of postural stability, and whether the indicators of stability were different in trials carried out while the participants were barefoot and in ski boots.

\section{Material and methods}

The study involved twenty male students from the University of Physical Education in Warsaw who participated in a nine-day ski training camp. Every day, the participants spent five hours skiing, and during that time their feet and ankle joints were immobilized in ski boots. For comparison purposes, the participants were divided into two groups of ten: beginners who were on skis for the first time (age: $20.7 \pm 1.1$ years, body mass: $76.4 \pm 8.7 \mathrm{~kg}$, height: $184.4 \pm 6.1 \mathrm{~cm}$ ); and advanced skiers with several years of experience in skiing (age: $20.5 \pm 0.5$ years, body mass: $80.5 \pm 13.7 \mathrm{~kg}$, height: $184.5 \pm 9.5 \mathrm{~cm}$ ). Both groups participated in a similar ski training programme without any extra exercises focused on improving postural stability, except for those performed while learning to ski. 
All of the participants were informed about the purpose and methods of the study, as well as the possibility to withdraw from their participation in the experiment at any time. The study was approved by the Senate Research Ethics Committee of the University of Physical Education in Warsaw.

Tests of postural stability were conducted on the first and last day of the camp, in the same measurement conditions and at the same time of day. Measurements of the balance of the body were conducted on an AccuSway (AMTI, USA) stabilometric platform with a stable surface. the test protocols were carried out with the participants' eyes open and closed, while standing on two feet (30 s) and on each of the left and right lower limb (10 s each), in barefoot trials and in ski boots. The anterior-posterior $(\mathrm{A} / \mathrm{P})$ and the medial-lateral $(\mathrm{M} / \mathrm{L})$ sway indicators, as well as the length of the sway path of the COP (Centre of Pressure), were used in the analysis (Fig. 1). Lower values of the length of the COP path and body sways indicate a better degree of balance.

The base of support is an important parameter for determining a stable body posture. To compare the measurements carried out while standing barefoot and in ski boots, the participants were positioned within the same footprints in each trial. When standing on one foot, the base of support was formed by the contour of the foot or the sole of the ski boot, and its length and width was the length and width of the foot or the sole of the boot. When standing on two feet, the base of support was the entire space between the contours of both feet or ski boots. In this case, the length of the base of support was the same as the length of the foot or the boot, and its width was limited by the outer contours of both feet or the soles of both boots.

A statistical analysis was conducted using the Statistica Ver. 10 package. The normality of the value distribution was evaluated using the Shapiro-Wilk W test. As the values did not meet the conditions of a normal distribution, the significance of differences between the groups and the trials in boots and barefoot were evaluated using the Mann-Whitney U test and the Wilcoxon signed-rank test between successive measurements. The probability level $p<0.05$ was adopted as the boundary for the evaluation of the difference relevance.

\section{Results}

The study did not show any significant differences related to the sizes of the base of support between the groups of advanced and beginner skiers (Table 1). The shape of the sole of a ski boot was unified, which allowed for combinations of ski boots and bindings made by various a)

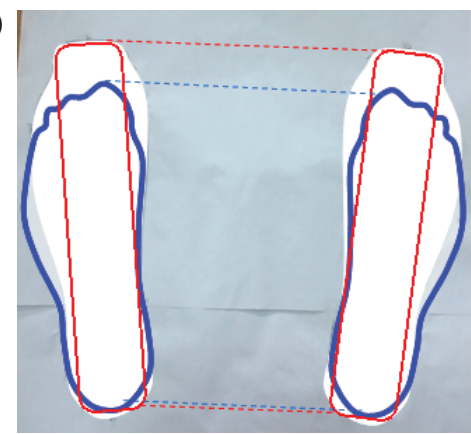

b)

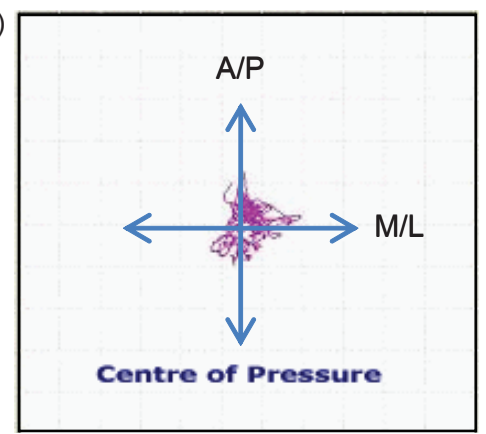

Fig. 1. a) The contour of the base of support in the measurements taken while the participants were barefoot and wearing ski boots; b) An example of the path of the centre of pressure (COP) of the feet on the ground

Table 1. The length and the width of the base of support while standing on one foot and two feet, barefoot and in ski boots (mean $\pm \mathrm{SD}$ )

\begin{tabular}{|c|c|c|c|c|c|c|}
\hline \multirow[b]{2}{*}{ Group } & \multicolumn{4}{|c|}{ Base of support on one foot } & \multicolumn{2}{|c|}{ Base of support on two feet ${ }^{c}$} \\
\hline & $\begin{array}{l}\text { Barefoot length } \\
{[\mathrm{cm}]}\end{array}$ & $\begin{array}{l}\text { Boot length } \\
{[\mathrm{cm}]}\end{array}$ & $\begin{array}{l}\text { Barefoot width } \\
{[\mathrm{cm}]}\end{array}$ & Boot width $[\mathrm{cm}]$ & $\begin{array}{l}\text { Barefoot width } \\
{[\mathrm{cm}]}\end{array}$ & Boot width $[\mathrm{cm}]$ \\
\hline Advanced & $28.4 \pm 1.1$ & $33.7 \pm 1.6^{\mathrm{a}}$ & $10.0 \pm 0.5$ & $7.0 \pm 0.0^{b}$ & $37.0 \pm 2.0$ & $36.6 \pm 2.1$ \\
\hline Beginners & $27.9 \pm 1.3$ & $32.9 \pm 1.4^{\mathrm{a}}$ & $9.8 \pm 0.5$ & $7.0 \pm 0.0^{b}$ & $36.4 \pm 3.3$ & $35.6 \pm 3.0$ \\
\hline
\end{tabular}

\footnotetext{
a base of support significantly longer than the barefoot base of support $(\mathrm{p}<0.001)$; ${ }^{\mathrm{b}}$ base of support significantly narrower than the barefoot base of support $(\mathrm{p}<0.001){ }^{\mathrm{c}}$ The length of the base of support while standing on two feet is the same as that of standing on one foot.
} 
manufacturers. The width of the sole was constant $(7 \mathrm{~cm})$, and the length was adjusted to the length of the skier's foot. Such a construction made the size of the base of support of the ski boot on average $5 \mathrm{~cm}(\Delta=18 \%)$ longer and $3 \mathrm{~cm}(\Delta=30 \%)$ narrower than a foot. In the trials that involved standing on two feet, a difference was observed only in the length, which was the same as the length of the base of support while standing on one foot.

In none of the tests conducted on both feet were significant differences in the length of the COP path observed between the group of beginners and the group of advanced skiers. In both groups, a statistically significant improvement in stability was observed after the training camp only while standing in ski boots, both with the eyes open and the eyes closed (Fig. 2). In the trials involving standing barefoot, there were no significant differences between the measurements taken at the beginning and at the end of the training programme. When maintaining the balance of the body while standing on two feet with their eyes open, the participants in both groups obtained better results in the trials that involved standing barefoot, both before and after the training camp. With the eyes closed, there was a significant difference in the stability between standing barefoot and in ski boots only in the group of beginners.

In the case of standing on one foot, a significant improvement in the stability of the body was observed after the training camp for those participants with their eyes open, in the measurements in ski boots while standing on the right lower limb (Fig. 3). It is noteworthy that a significant difference between standing barefoot and in ski boots was observed only for the participants with their eyes closed in the group of beginners (Fig. 4).

Table 2 shows the mean values of the sways of the body in the frontal $(\mathrm{M} / \mathrm{L})$ and sagittal $(\mathrm{A} / \mathrm{P})$ planes while standing on two feet. Significant differences between the sway ranges were observed only in the group of beginners. What is interesting is that in the measurements involving the participants standing barefoot with their eyes open, significantly greater sways in the sagittal plane were observed after the training camp than before it.

In the case of standing on one foot, no significant differences were observed in the sway range in the frontal and sagittal planes between the measurements taken before and after the training camp (Table 3 ). In both study groups, a better stabilisation was observed while the
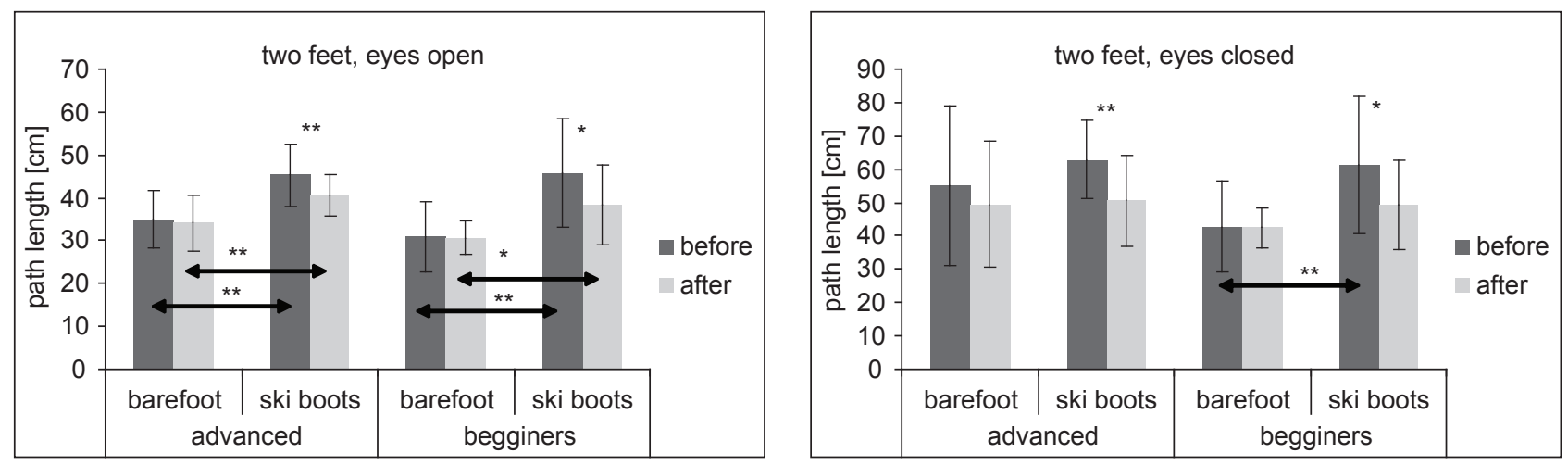

Fig. 2. The length of the COP path (mean $\pm \mathrm{SD}$ ) of the advanced and beginner skiers standing on two feet, with their eyes open and closed. $* \mathrm{p}<0.05, * * \mathrm{p}<0.01$
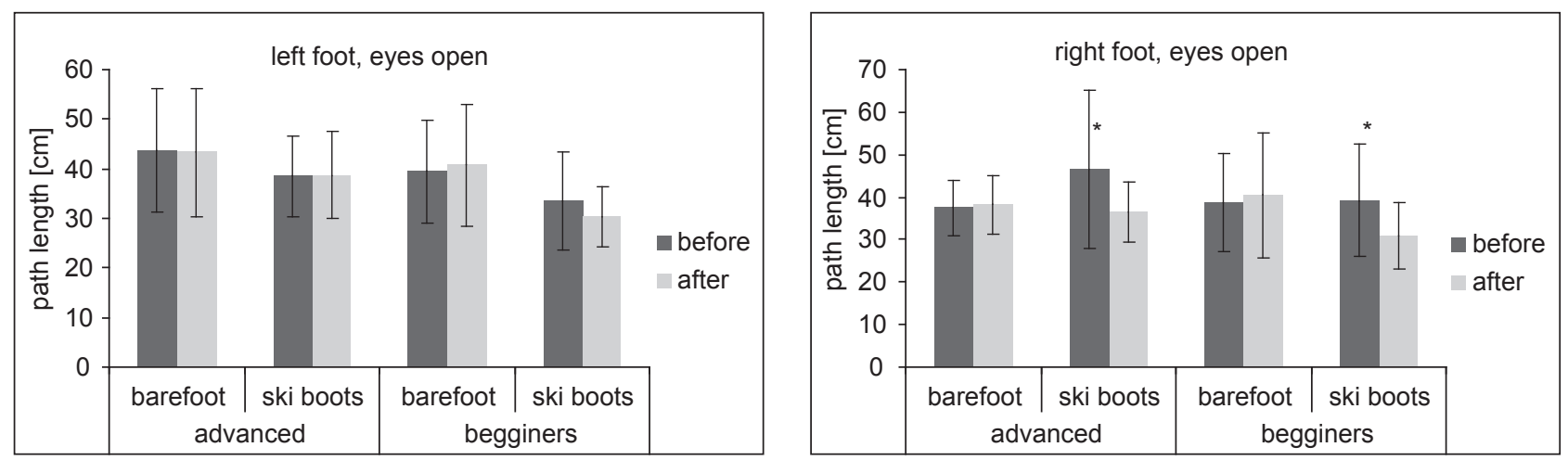

Fig. 3. The length of the COP path (mean $\pm \mathrm{SD}$ ) of the advanced and beginner skiers standing on one foot with their eyes open. $* \mathrm{p}<0.05$ 

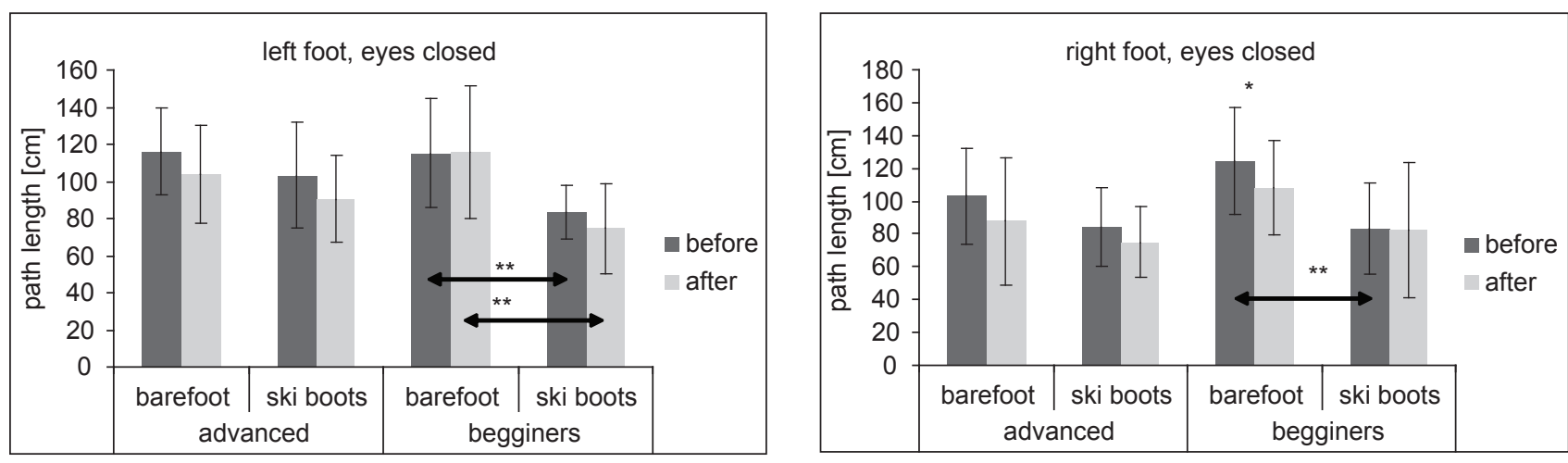

Fig. 4. The length of the COP path (mean $\pm \mathrm{SD}$ ) of the advanced and beginner skiers standing on one foot with their eyes closed. $* \mathrm{p}<0.05, * * \mathrm{p}<0.01$

Table 2. Mean sway range (mean $\pm \mathrm{SD}[\mathrm{cm}])$ in the frontal $(\mathrm{M} / \mathrm{L})$ and sagittal $(\mathrm{A} / \mathrm{P})$ planes while standing on two feet

\begin{tabular}{|c|c|c|c|c|c|c|}
\hline \multirow{2}{*}{ Position } & \multirow{2}{*}{ Direction } & \multirow{2}{*}{ Measurement } & \multicolumn{2}{|c|}{ Advanced } & \multicolumn{2}{|c|}{ Beginners } \\
\hline & & & Barefoot & Ski boots & Barefoot & Ski boots \\
\hline \multirow{4}{*}{ eyes open } & \multirow{2}{*}{$\mathrm{M} / \mathrm{L}$} & before & $0.55 \pm 0.23$ & $0.40 \pm 0.14$ & $0.39 \pm 0.11$ & $0.50 \pm 0.20$ \\
\hline & & after & $0.53 \pm 0.13$ & $0.51 \pm 0.13$ & $0.49 \pm 0.09$ & $0.37 \pm 0.12^{a}$ \\
\hline & \multirow{2}{*}{$\mathrm{A} / \mathrm{P}$} & before & $0.85 \pm 0.26$ & $0.73 \pm 0.17$ & $0.70 \pm 0.31$ & $0.90 \pm 0.51$ \\
\hline & & after & $0.83 \pm 0.35$ & $0.71 \pm 0.22$ & $1.02 \pm 0.30^{\mathrm{c}}$ & $0.75 \pm 0.21^{a}$ \\
\hline \multirow{4}{*}{ eyes closed } & \multirow{2}{*}{$\mathrm{M} / \mathrm{L}$} & before & $0.62 \pm 0.29$ & $0.49 \pm 0.21$ & $0.53 \pm 0.19$ & $0.55 \pm 0.24$ \\
\hline & & after & $0.55 \pm 0.22$ & $0.41 \pm 0.23$ & $0.51 \pm 0.13$ & $0.38 \pm 0.09^{\mathrm{a}, \mathrm{b}}$ \\
\hline & \multirow{2}{*}{$\mathrm{A} / \mathrm{P}$} & before & $1.25 \pm 0.38$ & $1.27 \pm 0.55$ & $1.14 \pm 0.47$ & $1.24 \pm 0.54$ \\
\hline & & after & $1.32 \pm 0.64$ & $1.23 \pm 0.79$ & $1.26 \pm 0.37$ & $1.03 \pm 0.44$ \\
\hline
\end{tabular}

a sway range significantly $(\mathrm{p}<0.05)$ lower in ski boots than without boots; ${ }^{\mathrm{b}}$ sway range significantly $(\mathrm{p}<0.05)$ lower than before the training programme; ${ }^{c}$ sway range significantly $(\mathrm{p}<0.05)$ higher than before the training programme

participants were standing in ski boots than barefoot, mainly in the sagittal plane $(\mathrm{A} / \mathrm{P})$ and in the trials with their eyes closed.

\section{Discussion}

The purpose of the design of a ski boot is to restrict the mobility within the ankle joint, especially in the frontal plane, which results in the exclusion of a significant element from the process of maintaining balance. A larger base of support while standing in ski boots should have a positive effect on the stability of the body. However, regardless of their skiing skills, while the participants were standing on two feet with their eyes open, the ski boots significantly worsened the conditions of maintaining a stable body posture. Therefore, it can be assumed that stiffening the ankle joint impedes a stable posture, because the other stabilising muscles must take over the functions that control the sways of the body. With the eyes closed, this difference was significant only in the group of beginners and only in the measurements taken before the training camp. An inverse relationship, although it was statistically confirmed only for the beginners with their eyes closed, was observed while they were standing on one foot. This time, the length of the COP path, which indicated the level of balance, was lower in the measurements of the participants in ski boots. When standing on one foot, the base of support is reduced several times when compared to standing on two feet, while the body mass remains the same. Due to its anatomical structure, the musculoskeletal system of the ankle joint is the weakest element in maintaining a stable erect posture because the torques of the plantar flexors of the foot that are normalised for the body weight oscillate within a few newton metres [7]. The majority of studies represented in the literature also indicate the lack of asymmetry in the strength of the groups of muscles that flex and straighten the foot [6]. Therefore, stiffening the ankle joint had a positive effect on the balance parameters while standing on one foot. 
Table 3. Mean sway range (mean $\pm \mathrm{SD}[\mathrm{cm}])$ in the frontal $(\mathrm{M} / \mathrm{L})$ and sagittal $(\mathrm{A} / \mathrm{P})$ planes while standing on one foot

\begin{tabular}{|c|c|c|c|c|c|c|}
\hline \multirow{2}{*}{ Position } & \multirow{2}{*}{ Direction } & \multirow{2}{*}{ Measurement } & \multicolumn{2}{|c|}{ Advanced } & \multicolumn{2}{|c|}{ Beginners } \\
\hline & & & Barefoot & Ski boots & Barefoot & Ski boots \\
\hline \multirow{4}{*}{$\begin{array}{l}\text { Left leg eyes } \\
\text { open }\end{array}$} & \multirow{2}{*}{$\mathrm{M} / \mathrm{L}$} & before & $0.97 \pm 0.25$ & $1.06 \pm 0.49$ & $1.00 \pm 0.24$ & $0.88 \pm 0.29$ \\
\hline & & after & $1.16 \pm 0.21$ & $1.08 \pm 0.40$ & $0.92 \pm 0.19$ & $1.13 \pm 0.61$ \\
\hline & \multirow{2}{*}{$\mathrm{A} / \mathrm{P}$} & before & $1.41 \pm 0.84$ & $0.99 \pm 0.39$ & $1.16 \pm 0.40$ & $0.86 \pm 0.26$ \\
\hline & & after & $1.12 \pm 0.14$ & $1.06 \pm 0.36$ & $1.40 \pm 0.40$ & $0.78 \pm 0.14 \mathrm{a}$ \\
\hline \multirow{4}{*}{$\begin{array}{l}\text { Left leg eyes } \\
\text { closed }\end{array}$} & \multirow{2}{*}{$\mathrm{M} / \mathrm{L}$} & before & $2.18 \pm 0.35$ & $2.50 \pm 0.63$ & $2.21 \pm 0.37$ & $2.07 \pm 0.49$ \\
\hline & & after & $2.12 \pm 0.27$ & $2.30 \pm 0.62$ & $2.43 \pm 0.72$ & $1.92 \pm 0.59$ \\
\hline & \multirow{2}{*}{$\mathrm{A} / \mathrm{P}$} & before & $3.92 \pm 1.65$ & $2.52 \pm 0.81^{\mathrm{a}}$ & $4.02 \pm 1.43$ & $2.49 \pm 0.74 \mathrm{a}$ \\
\hline & & after & $3.44 \pm 1.41$ & $2.14 \pm 0.67^{\mathrm{a}}$ & $4.04 \pm 1.63$ & $2.11 \pm 0.64 \mathrm{a}$ \\
\hline \multirow{4}{*}{$\begin{array}{l}\text { Right leg } \\
\text { eyes open }\end{array}$} & \multirow{2}{*}{$\mathrm{M} / \mathrm{L}$} & before & $0.87 \pm 0.28$ & $1.02 \pm 0.38$ & $0.85 \pm 0.20$ & $0.90 \pm 0.34$ \\
\hline & & after & $0.95 \pm 0.34$ & $0.89 \pm 0.24$ & $1.00 \pm 0.23$ & $0.80 \pm 0.19$ \\
\hline & \multirow{2}{*}{$\mathrm{A} / \mathrm{P}$} & before & $0.95 \pm 0.26$ & $1.37 \pm 0.62$ & $1.32 \pm 0.35$ & $1.11 \pm 0.29$ \\
\hline & & after & $1.20 \pm 0.25$ & $1.07 \pm 0.27$ & $1.27 \pm 0.42$ & $1.16 \pm 0.83$ \\
\hline \multirow{4}{*}{$\begin{array}{l}\text { Right leg } \\
\text { eyes closed }\end{array}$} & \multirow{2}{*}{$\mathrm{M} / \mathrm{L}$} & before & $2.20 \pm 0.45$ & $1.82 \pm 0.43^{\mathrm{a}}$ & $2.74 \pm 0.47$ & $1.90 \pm 0.43^{a}$ \\
\hline & & after & $2.44 \pm 0.86$ & $2.10 \pm 0.90$ & $2.74 \pm 0.58$ & $1.79 \pm 0.30^{a}$ \\
\hline & \multirow{2}{*}{$\mathrm{A} / \mathrm{P}$} & before & $3.71 \pm 1.30$ & $2.29 \pm 0.53^{\mathrm{a}}$ & $4.41 \pm 0.97$ & $2.27 \pm 0.68^{a}$ \\
\hline & & after & $3.47 \pm 1.54$ & $1.97 \pm 0.53^{a}$ & $4.19 \pm 1.45$ & $2.41 \pm 0.80^{\mathrm{a}}$ \\
\hline
\end{tabular}

${ }^{a}$ sway range significantly $(\mathrm{p}<0.05)$ lower in ski boots than barefoot

When analysing the range of forward/backward and sideways body sways while standing on two feet, interesting dependencies can be observed in the group of beginners. Before the beginning of the training programme, the participants demonstrated a lower sway range in both the frontal and sagittal planes when standing in a natural position on both feet. However, after nine days of the ski training programme, a lower sway range was observed in the measurements performed while in ski boots. This may indicate that a specific adaptation of the neuromuscular system to the stiffening of the ankle joint caused by the ski boots had occurred, which is positive for the function of maintaining balance in skiing.

A similar phenomenon was observed by Noé and Paillard [20], who studied the postural stability of amateur skiers and members of a national ski team by taking their measurements with and without ski boots. It turned out that the amateur skiers demonstrated better parameters for postural stabilography than the professional skiers in the measurements performed without boots. However, when wearing ski boots, the professional skiers obtained significantly better balance values, which may indicate an impact of the long-term use of ski boots on the emergence of balancing habits, but only in the proper conditions for the sport. Similarly, in a study by Zemková [26], the skiers demonstrated a better stability than fit non-skiers while standing in ski boots.
In the conducted study, no statistically significant differences in the balance parameters were observed between the beginners and advanced skiers. Several years of experience in practicing a certain physical activity may have a positive effect in terms of improvements in coordination, strength or the range of movement, which should increase that person's balance skills. In many sports, such as shooting, football or golf, training experience has been shown to have a positive effect on the process of maintaining balance. However, there are sports in which the level of technical advancement does not determine the body's level of stability. These include surfing, judo, snowboarding and alpine skiing [11, 21].

In the comparison of the parameters of the stability of the body before and after the training camp, significant changes were observed only in the length of the path of the pressure of the feet on the ground, and only in a standing position in ski boots. It can therefore be assumed that the improvement in balance occurred only in the trials where the ankle joint was stiffened, which was practised during the nine-day training programme. One should bear in mind that in this study, the measurements of postural stability were taken on a stable surface. In a very similar experiment involving a seven-day training camp, Wojtyczek et al. [25] demonstrated a significant improvement in the participants' balance after the end of a ski training 
programme, but their evaluation of balance was carried out on an unstable surface.

Wearing ski boots for a few hours can lead to a weakening of the muscles that operate within the ankle joint. This works as though one joint was excluded from the locomotive function. Dudek et al. [5] demonstrated that the stabilising function in the process of maintaining balance was significantly weakened after an injury to the ankle joint which excluded it from locomotion for some time. Also, according to Caplan et al. [3], the muscle groups that determine strength and are responsible for the function of stability in the ankle joint are very sensitive to changes caused by immobilisation. They found that immediately after immobilising the ankle joint for a week, the balance parameters were $50 \%$ lower than before the immobilisation. However, these parameters returned to the baseline values in just two days after the immobilisation ended. It should be noted that when the participants were standing on one foot in a ski boot in the conducted study, their M/L sways were lower than while standing barefoot, despite having a significantly narrower base of support. Therefore, the stiffening of the ankle joint had a positive effect on the sideways sway range.

Given the stiffness of ski boots, part of the strain resulting from maintaining a stable body posture is transferred from the ankle joint to the boot. Thus, when skiing, the role of the ankle joint in the process of controlling balance is greatly limited, and the knee joints became the last moving element in the biokinematic chain of the lower limbs that controls the position of the body [12]. As a result of immobilising the foot in a ski boot, the majority of the functions that determine the movement of the centre of mass are taken over by the muscles that operate within the knee and hip joints. Scott et al. [22] demonstrated that during ski turns, the angular changes in the knee and hip joints can reach $50^{\circ}$, while in the ankle joint the oscillation is only a few degrees.

In the present study, significantly more differences and changes in the parameters of the stability of the body were observed in the group of beginner skiers. Two mechanisms for these changes can be observed: first, there was an adaptation of the musculoskeletal system to new conditions, i.e. putting on ski boots; and second, there was a weakening of the foot and ankle joint complex caused by hours of its stiffening and exclusion from the function of balancing the body. Hence, there was an improvement in balance while wearing boots, and a worsening of balance while standing barefoot. Some of these changes and differences were on the borderline of statistical significance and must be confirmed on a more numerous study group. This is especially true given that in a study by Tchórzewski et al. [24], the restriction in the mobility of the ankle joint in beginner skiers that resulted from wearing ski boots caused a decrease in the stability of the body. Another study demonstrated that measurements in ski boots with skis attached had a positive effect on the postural stability indicators [9].

In summary, it can be stated that the restriction on the mobility within the ankle joints had a significant impact on the training-induced changes in postural stability while the participants were standing on two feet, in both beginner and advanced alpine skiers. However, in the trials where the participants stood on one lower limb, balance improved mainly in the beginners. This may indicate the need for the body to adapt to wearing ski boots and to learning the new activity of alpine skiing. Nine days of skiing had a positive effect on the postural stability only in measurement conditions that were similar to those in which this stability was practiced, i.e. in the measurements that involved wearing ski boots.

\section{References}

1. Allum J.H.J., N.T. Shepard (1999) An overview of the clinical use of dynamic posturography in the differential diagnosis of balance disorders. J. Vest. Res., 9(4): 223-252.

2. Böhm H., V. Senner (2008) Effect of ski boot settings on tibio-femoral abduction and rotation during standing and simulated skiing. J. Biomech., 41(3): 498-505.

3. Caplan N., A. Forbes, S. Radha, S. Stewart, A. Ewen, A. St Clair Gibson, D. Kader (2015) Effects of 1 week of unilateral ankle immobilization on plantar-flexor strength, balance and walking speed: a pilot study in asymptomatic volunteers. J. Sport Rehabil., 24(2): 156-162. DOI:10.1123/jsr.2013-0137

4. DiStefano L.J., M.A. Clark, D.A. Padua (2009) Evidence supporting balance training in healthy individuals: a systemic review. J. Strength Cond. Res., 23(9): 2718-2731. DOI:10.1519/JSC.0b013e3181c1f7c5

5. Dudek K., M. Drużbicki, G. Przysada, D. Śpiewak (2014) Assessment of standing balance in patients after ankle fractures. Acta Bioeng. Biomech., 16(4): 59-64. DOI:10.5277/ABB-00061-2014-01

6. Fish M., J. Milligan, J. Killey (2014) Is it possible to establish reference values for ankle muscle isokinetic strength? A meta-analytical study. Isokinet. Exerc. Sci., 22(2): 85-97.

7. Fischer S.L., B.R. Picco, R.P. Wells, C.R. Dickerson (2013) The roles of whole body balance, shoe-floor friction, and joint strength during maximum exertions: searching for the "Weakest Link". J. Appl. Biomech., 29(1): 1-11.

8. Gorman P.P., R.J. Butler, M.J. Rauh, K. Kiesel, P.J. Plisky (2012) Differences in dynamic balance scores in one sport versus multiple sport high school athletes. Int. J. Sports Phys. Ther., 7(2): 148-153. 
9. Gustyn M. (2012) The impact of ankle joint stiffening by ski equipment on maintenance of body balance. Pol. J. Sport Tourism., 19: 168-177.

10. Hébert-Losier K., M. Supej, H. Holmberg (2014) Biomechanical factors influencing the performance of elite alpine ski racers. Sports Med., 44(4): 519-533. DOI:10.1007/s40279-013-0132-z.

11. Hrysomallis C. (2011) Balance Ability and Athletic Performance. Sports Med., 41(3): 221-232.

12. Klous M., E. Müller, H. Schwameder (2014) Three-dimensional lower extremity joint loading in a carved ski and snowboard turn: a pilot study. Comput. Math. Methods Med., 1-13. DOI:10.1155/2014/340272.

13. LeMaster R. (2010) Ultimate skiing. Blue Sky, Inc.

14. Lynn S., R. Padilla, K. Tsang (2012) Differences in static - and dynamic-balance task performance after 4 weeks of intrinsic-foot-muscle training: the short-foot exercise versus the towel-curl exercise. J. Sport Rehabil., 21(4): 327-333.

15. Marius V. (2012) Comparative study concerning the balance development at adults by means specific to sport games. Ovidius university annals, series physical education and sport/science, movement and health, 12(2): 496-501.

16. Müller E., H. Schwameder (2003) Biomechanical aspects of new techniques in alpine skiing and ski-jumping. J. Sport Sci., 21(9): 679-692.

17. Nashner L.M. (1993) Practical biomechanics and physiology of balance. In: G.P. Jacobson, C.W. Newman, J.M. Kartush (eds.). Handbook of balance function testing. Mosby Year Book, St. Louis: 261-279.

18. Nemec B., T. Petrič, J. Babič, M. Supej, (2014) Estimation of alpine skier posture using machine learning techniques. Sensors, 14(10): 18898-18914. DOI:10.3390/ s141018898.

19. Noé F., D. Amarantini, T. Paillard (2009) How experienced alpine-skiers cope with restrictions of ankle de- grees-of-freedom when wearing ski-boots in postural exercises. J. Electromyogr. Kinesiol., 19(2): 341-346.

20. Noé F., T. Paillard (2005) Is postural control affected by expertise in alpine skiing? Br. J. Sports Med., 39: 835-837. DOI: 10.1136/bjsm.2005.018127.

21. Platzer H., C. Raschner, C. Patterson, S. Lembert (2009) Comparison of physical characteristics and performance among elite snowboarders. J. Strength Cond. Res., 23(5): 1427-1432. DOI:10.1519/JSC.0b013e3181aa1d9f.

22. Scott N.W., T. Yoneyama, H. Kagawa, M. Takahashi (2004) Measurement of joint motion and acting forces on a top athlete skiing. Eng. Sport, 5(1): 1494-1500.

23. Spörri J., J. Kröll, H. Schwameder, C. Schiefermüller, E. Müller (2012) Course setting and selected biomechanical variables related to injury risk in alpine ski racing: an explorative case study. Br. J. Sports Med., 46(15): 1072-1077.

24. Tchórzewski D., P. Bujas, A. Jankowicz-Szymańska (2013) Body posture stability in ski boots under conditions of unstable supporting surface. J. Hum. Kinet., 38: 33-44.

25. Wojtyczek B., M. Pasławska, C. Raschner (2014) Changes in the balance performance of Polish recreational skiers after seven days of alpine skiing. J. Hum. Kinet., 44: 29-40.

26. Zemková E. (2014) Sport-Specific Balance. Sports Med., 44(5): 579-590.

\section{Received 01.12.2015 \\ Accepted 29.02.2016}

(C) University of Physical Education, Warsaw, Poland

\section{Acknowledgments}

The study was financed by the Ministry of Science and Higher Education as part of research project DS-199. 